\title{
Dual Mode Shock-Expansion/Reflected-Shock Tunnel
}

\author{
John I. Erdos*, Robert J. Bakos ${ }^{\star *}$, Anthony Castrogiovanni+ \\ GASL \\ and \\ R. Clayton Rogers++ \\ NASA Langley Research Center
}

\begin{abstract}
NASA's HYPULSE facility at GASL has been reconfigured to permit free jet testing of the Hyper-X flowpath at flight Mach numbers of 7 and 10 . Among the required changes are addition of a converging-diverging nozzle to permit operation in a reflected shock tunnel mode, a $7 \mathrm{ft}$. diameter test cabin and a $30 \mathrm{in}$. diameter contoured nozzle. However, none of these changes were allowed to interfere with rapid recovery of the prior shockexpansion tunnel mode of operation, and indeed certain changes should enhance facility usefulness and productivity in either mode. A previously-developed shockinduced detonation mode of driving the facility has been successfully applied to both reflected shock tunnel operation at Mach 10 flight conditions, with tailored interface operation, and shock-expansion tunnel operation at flight conditions corresponding to Mach numbers from 12 to 25 . Tailored interface operation at Mach 7 has been achieved with an unheated helium driver.

In the present paper, the rationale for a dual mode shock expansion/reflected shock tunnel is discussed, and the capabilities and limitations for each mode are outlined. The physical changes in the HYPULSE facility to achieve dual mode capability are also described. Limited calibration data obtained to date in the new reflected shock tunnel mode are presented and the anticipated flight simulation map with dual mode operation is also outlined.
\end{abstract}

\footnotetext{
${ }^{*}$ Vice-President, Associate Fellow AIAA

${ }^{* *}$ Principal Scientist; Member AIAA

${ }^{+}$Principal Scientist; Member AIAA

${ }^{++}$Hypersonic Airbreathing Propulsion Branch

Senior Member AIAA
}

\section{Background and Motivation}

NASA's HYPULSE Facility is a large-scale shock-expansion tunnel (SET) operated by GASL as part of its ramjet-scramjet test complex. It has proven to be a versatile test facility for development of hypersonic combustion technology at flight Mach numbers from 12 to 19 , using a semi-direct connect test technique, as well as for real gas studies of external aerodynamics. Recent implementation of a detonative mode of driving the facility provides sufficient pressure to enable free-jet testing of complete engine models 1 , as well as increasing the Reynolds number capability. Exploratory calibration tests in the shockexpansion tunnel mode, aimed at supporting free-jet development of new engine designs employing shock-induced combustion at Mach numbers of 14 and higher, have been carried out2. However, this development has been overshadowed by the new Hyper-X program3 in which NASA plans to flight test a scramjet engine at Mach 5, 7 and 10. Accordingly, the HYPULSE facility has been reconfigured to enable free jet testing of the Hyper-X engine in this range of Mach numbers, most specifically at Mach 10 .

Operation of the facility in a shock-expansion tunnel (SET) mode at total enthalpy levels corresponding to flight Mach numbers of 5 to 10 is inappropriate for several reasons: (1) the required total enthalpies and total pressures are well within the range of a moderate performance reflected shock tunnel (RST), (2) at these conditions

Copyright (C) 1997 by the American Institute of Aeronautics and Astronautics, Inc. All rights reserved. 
reflected shock operation provides about 10 times the test time of shock-expansion operation, and (3) dissociation in the plenum, recombination in the nozzle and throat survival, which affect RST performance at high enthalpy-high pressure conditions, are non-issues at these conditions.

Therefore, it was decided to reconfigure HYPULSE for dual operating mode capability: reflected-shock tunnel (RST) below about Mach 11 and shock-expansion tunnel (SET) above about Mach 11. All inplace engine test infrastructure, including systems for fuel heating and supply ${ }^{4}$, fuel plume imaging $^{5}$ and water vapor measurement ${ }^{6}$ will be retained.

\section{Comparison of RST and SET Attributes and Requirements}

\section{Operating Cycles}

The operation of a reflected-shock tunnel (RST) and a shock-expansion tunnel (SET) is best described by means of their classical, inviscid wave diagrams. In both cases, the nozzle portions of the facilities employ steady state expansions from the conditions produced at the end the shock or acceleration tube, following a brief transient process to start the nozzle flow. For the present discussion, operation of the two types of facilities can be described in terms of the wave processes in the shock tube and shock and acceleration tubes, for a RST and SET respectively, and the nozzles will be neglected. For the sake of comparison, we will assume in this discussion that both facilities have equal overall lengths, $23.5 \mathrm{~m}$, as that will be the case for a single facility with dual capabilities and the selected value corresponds to that of the HYPULSE facility. Furthermore, in view of the intended use of the RST for simulation of Mach numbers generally below 11 and the SET for higher Mach numbers, the wave diagrams have been prepared for a RST at a Mach 10 total enthalpy level, which is controlled by the primary shock speed, and for a SET at a Mach 15 total enthalpy level, which is controlled by the combination of primary and secondary shock speeds.
Also for the sake of the present comparison, a downstream-running detonation wave has been assumed as the method for heating the driver gas. In both cases, a mixture of $30 \%$ hydrogen and $15 \%$ oxygen forms the detonable mixture. For RST operation with a "tailored interface" this mixture is diluted in $55 \%$ argon. (The actual hydrogen-oxygen levels have been somewhat reduced from the experimentally used levels to approximate viscous attenuation of the shock speed.) The "tailored interface" is a well-known procedure for tailoring the sound speeds in the driver and driven gases such that their interface is just brought to rest by the reflected shock, and therefore produces a pool of stagnant gas at the end of the shock tube which becomes the plenum for the nozzle expansion. With a downstream running detonation drive, the so-called "Taylor rarefaction" wave system that follows a free-running detonation wave both attenuates the speed of the resulting incident shock wave through the test gas and produces a complex system of reflected waves off the interface. This wave system is depicted in Figure 1. In this example, a nozzle throat which is one-third the diameter of the tube has been assumed, which is about the largest throat to tube diameter ratio which is practical. Drainage of gas from the plenum section is fairly rapid, and the useful test period ends after about 5 msec with arrival of the driver gas at the nozzle throat. In reality, boundary layer interactions caused by the reflected shock passing into the moving driven and driver gases permits driver gas to jet forward of the inviscid interface location, resulting in premature contamination of the driven (test) gas and corresponding reduction in the useful test period. This phenomenon will be further discussed later.

In so-called "under-tailored" operation the interaction of the reflected shock and the interface causes a series of reflected expansion waves which result in dropping pressure in the nozzle plenum section, but permit the interface to move away from the end of the tube and therefore produce a longer test period before driver gas drainage or contamination occurs. On the other hand, "over-tailored", or "equilibrium interface", 
operation produces a series of reflected shock waves which result in an increasing pressure in the plenum, but a shorter test period before driver gas contamination occurs. These induced compression or expansion systems can be used to offset the reflected Taylor rarefaction waves. In view of the complex interactions produced by the downstream-running detonation wave, "tailoring" is also more complex, and a degree of trial-and-error experimentation is required to achieve acceptably uniform test conditions. Examples will be shown later.

It should also be pointed out that the detonation waves produced in the HYPULSE facility are initiated by a shock wave which is driven into the detonable mixture from a cold helium section which occupies the first $4.9 \mathrm{~m}$ of the driver section depicted in these diagrams. The KASIMIR code (obtained from RWTH Aachen) used to generate these diagrams can not model shock-induced detonation, so the present set of wave diagrams neglect this aspect of the flow. However, calculations and data show that the reflected waves from the breech end of the cold helium driver section do not reach the downstream end of the shock tube in time to alter the present results.

In all the cited RST operating modes, the distance between the interface and the primary shock decreases as the shock speed increases. Therefore, the distance that the interface stands off from the end of the shock tube following shock reflection decreases as the primary shock speed increases, i.e., as the total enthalpy of the stagnated gas increases. Consequently, useful test time per unit length of shock tube decreases with increasing total enthalpy. The inviscid estimate of the useful test time is the most conservative, and the premature contamination caused by the driver gas boundary layer jetting into the test gas also becomes more severe as the shock strength increases.

SET operation is depicted in Figure 2 for a Mach 15 condition. In this example, the same $\quad 30 \%-15 \% \quad$ hydrogen-oxygen concentration in the driver gas as assumed for RST operation has been used, but the diluent is helium rather than argon. In SET mode, arrival of the driver gas interface and driver gas contamination is not a concern. However, the (ideal) useful test time is the period between arrival of the acceleration gas interface and the secondary or reflected expansion waves. Obviously, this period, at Mach 15 conditions, namely about 0.45 msec, is much shorter than that for RST operation at Mach 10 . However, the parameter which governs flow establishment is not test time but rather the product of test time and flow velocity, commonly called the "slug length." Experimentally determined values of test time and "slug length" previously obtained in SET mode in HYPULSE are compared with the current values obtained in RST mode (which will be further discussed later) in Figure 3. The experimental values in RST mode are based on the best current measurements of the onset of driver gas contamination, which (as usual) turns out to be the limiting factor on useful test time. The rates of change of the test duration and slug length with simulated flight Mach number is such that the transition from one mode to the other becomes imperative at some sufficiently high Mach number which depends on facility size. In the present case, that transition is also driven by the relatively low pressure rating of the shock tube, namely 7700 psia, which necessarily limits the total pressure to no more than that value. In SET mode, considerably higher values of total pressure are readily attainable.

In reality, RST operation at very high enthalpy levels is also usually limited by other considerations, especially nozzle throat survival. In the SET case, the nozzle is simply a divergent (throat-less) section which begins at the end of the acceleration tube, and may capture either the entire tube flow1 or only the central core7. In either case, heating and erosion of the facility walls is much less severe than in a RST at comparable conditions, and becomes a limiting consideration for a SET at only extremely high, super-orbital flight conditions. 


\section{Optimum Component Sizing}

In any wave-driven facility, as the wave speed changes the optimum length of the components to maximize test time changes. For a RST, the driver tube is ideally sized to permit the reflected expansion waves from the breech end of the driver to reach the nozzle throat at the same time as the driver gas interface. If the driver vessel is too short, the reflected expansions determine the useful test time rather than drainage of the driven gas. For the detonative driver mode, lengthening the driver tube also reduces the rate of pressure decay through the Taylor rarefaction waves which follow the detonation. Thus, for RST operation, the ideal ratio of driver to driven tube lengths decreases as the primary shock speed (and total enthalpy level) increases. For a SET much the same situation prevails. However, in this case the ratio of shock to acceleration tube must also be taken into account, such that all reflected expansion waves and the secondary expansion fan all arrive simultaneously at the end of the acceleration tube.

Another parameter must be considered in sizing components. The growth of boundary layers on the tube walls results in attenuation of the shock speeds and acceleration of the interface ${ }^{8}$. The two speeds approach each other at a ratio of tube length to diameter of about 100 , and a ratio on the order of about 60 is usually considered about ideal for tolerable degree of boundary layer growth.

It can be seen from the preceding discussion that at low total enthalpy levels, corresponding to flight Mach numbers of 10 or less, a well-sized RST has a relatively long driver tube and relatively short driven tube. On the other hand, at high total enthalpy levels, corresponding to flight Mach numbers of 12 or greater, a well-sized SET has a relatively short driver and relatively long combination of shock tube and acceleration tube. Thus, it is possible to have a facility which achieves reasonable, if not optimum, relative tube lengths for both low enthalpy RST operation and high enthalpy SET operation, within a given overall length. What defines the various tube lengths are, of course, the locations of diaphragms to contain the various gases at their proper fill pressures. Therefore, a facility having dual mode capability must have the ability to locate the diaphragms at a variety of stations.

\section{Operation}

The parameters which control operation in either RST or SET mode are the composition of the gases in the various components and their fill pressures. In both cases, we will assume the test gas (the driven gas) is air. However, in both RST and SET operation, other gases can be used for various test purposes. In general, light (high sound speed) gases are used in the driver to obtain the highest possible shock speed for a given fill pressure ratio between the driver and driven tubes. In the RST case, this condition must be tempered with respect to the "tailoring" requirements. In SET operation, there is no "tailoning" requirement, but the composition of the driver gas can still be varied to adjust the ratio of primary and secondary shock speeds while maintaining desired fill pressures.

\section{Selection of SET Parameters}

For SET operation with a driver of given sound speed, the driver to shock tube pressure ratio fixes the primary shock strength. The ratio of pressures between the shock and acceleration tubes then dictates the secondary shock strength and the strength of the secondary expansion. Both the primary shock and the unsteady expansion add energy to the test flow; the former primarily in terms of temperature or thermal energy and the latter primarily in the form of velocity or kinetic energy. Thus, for a required test flow stagnation enthalpy, the portions of energy added by the primary shock and by the unsteady expansion are chosen by adjusting the tube fill pressures to reach a desired local test flow Mach number.

This adjustment can not be done, however, without consideration of the steady flow test time. For given tube lengths there exists a ratio of secondary to primary shock speeds which maximizes test time and this ratio is 
practically independent of the test flow enthalpy level. As an example, in the HYPULSE facility operating with a 7 m shock tube and $14 \mathrm{~m}$ acceleration tube, a secondary-to-primary shock speed ratio of approximately two has been found to give maximum test time over a test flow enthalpy range from 12 to $25 \mathrm{MJ} / \mathrm{kg}$. Therefore, to achieve both a desired test flow local Mach number and maximum test time, the lengths of the shock and acceleration tubes must also be adjustable. In the HYPULSE facility, the secondary diaphragm can be located at any of several tube joints spaced every 15 or 30 tube diameters. Consequently, to access lower local Mach number test conditions in HYPULSE in the 9-12 MJ/kg enthalpy range, the diaphragm is moved downstream yielding a $10 \mathrm{~m}$ shock tube and $11 \mathrm{~m}$ acceleration tube.

Noteworthy for SET operation is that the sole role of the driver is to generate the primary shock wave and sustain its strength. It has no further role in setting the state or temporal behavior of the test flow. Consequently, to maximize post-primary shock pressure, and ultimately test section pressure for a given driver fill pressure, the preferred choice for a SET driver will have high sound speed regardless of the other test flow conditions which are sought.

In light of this, use of a detonative combustion driver has been found to be an effective means to drive strong shocks in the HYPULSE facility. To achieve the highest driver performance, stoichiometric hydrogen oxygen mixtures with helium diluent are used in SET mode. A free-running Chapman-Jouguet detonation is initiated by a shock wave driven from a conventional light-gas (helium) driver and runs forward or downstream toward the shock tube. In this so-called shock-induced detonation (SID) driver, the driver gas properties immediately following the C-J wave decay through the Taylor rarefaction coupled to the detonation. It has been found, however, that this decay produces no significant primary shock speed decay and only modest but predictable pressure variation in the test flow. ${ }^{2}$

\section{Selection of RST Parameters}

Operation in RST mode is more straightforward than SET mode because there is no acceleration tube and therefore one less degree of freedom for adjusting of test conditions. The sound speed of the driver gas and the ratio of driver-to-shock tube fill pressures determine the strength of the primary shock which in turn determines the pressure and enthalpy of the stagnant gas behind the reflected shock. Adjustment of the expanded test flow local Mach number is achieved by geometric variation of the hypersonic nozzle area ratio.

Unfortunately, conditions in the postreflected shock reservoir will rapidly decrease or increase with time if the properties on either side of the drivergas/test-gas interface are not properly chosen or "Ïtailored" due to waves generated by the interaction of the interface and reflected shock. For room temperature helium driving a shock wave into air it is well known that "tailored interface" operation occurs at a primary shock Mach number of $\mathrm{M}_{\mathrm{s}}=3.4$, yielding an equivalent simulated flight Mach number of approximately $M_{\infty}=6.0$. Small deviations from tailored operation are usually acceptable as, for instance, in HYPULSE where a primary shock Mach number of $M_{s}=4.0$ has been found to yield acceptably long durations of virtually constant test flow at a simulated flight Mach number of $M_{\infty}=7.0$.

To reach higher Mach numbers, light, higher sound speed driver gas is necessary. In HYPULSE we have adapted the SID-driver technique for tailored interface RST operation and demonstrated tailored operation at simulated Mach 10 flight conditions. Application of the SID-driver to RST is different from SET implementation in two important respects.

Because the available steady flow test times in a RST mode are perhaps an order of magnitude longer than in a SET mode, the driver must sustain the conditions behind the shock wave (and in the reservoir which is formed) for a much longer period. With a forward-running detonation wave driver, this 
necessitates either over-driving the detonation to create a perfectly uniform region of detonation products, or using the region of uniform driver gas properties which forms behind the Taylor rarefaction in the SID-driver to sustain the reservoir pressure. This uniform property region is indicated as the "plateau" region on the top of Figure 4 which is an instantaneous pressure vs. distance plot for a typical SID-driver. It indicates that upon rupture of the diaphragm separating the helium from the detonable mixture the $\mathrm{C}-\mathrm{J}$ wave is initiated. The Taylor rarefaction waves in the post C-J products form to equilibrate the velocity and pressure at the interface when the expanded light gas driver is below that necessary to overdrive the detonation. A perfectly driven detonation condition, shown in the second plot, is such that the helium pressure in the light-gas chamber is sufficiently high that, upon expansion after diaphragm rupture, its pressure and velocity just match those behind the free-running $\mathrm{C}-\mathrm{J}$ wave in the detonation tube, ie. the Taylor rarefaction is canceled. If the light-gas drives pressure is higher still, the detonation is overdriven.

The advantage of utilizing the pressure plateau region in the SID technique is that much higher driver performance can be attained within the maximum-operatingpressure bounds of the light-gas driver and detonation tubes. The disadvantage, as indicated previously, is that Taylor rarefaction induces pressure nonuniformities in the test gas shortly after shock reflection from the shock tube end. However, in a practical sense, these nonuniformities occur during the period of nozzle flow start-up and therefore do not appreciably reduce useful test time in the facility.

A second difference in RST mode is the need to precisely adjust the driver gas sound speed such that tailored operation is achieved. Unlike the SET mode, the diluent gas cannot be chosen just to maximize the driven shock speed. We have found a mixture of $30 \%$ argon with stoichiometric hydrogen-oxygen as a detonable mixture yields optimum test time at the Mach 10 condition.
To compare the theoretical performance of RST driver techniques, Figures $5 a$ and $5 b$ show the effective driver pressure and sound speed of the detonation products in a perfectly driven detonation driver and SIDdriver, both using helium in the light-gas chamber. The "effective" pressure and sound speed are computed from the actual state of the detonation products by compressing them back to a zero-velocity state, and as such, account for the greater shock driving potential that the products have due to their forward velocity.

Examining the perfectly-driven case it is seen that for a typical choice of $30 \%$ argon as diluent gas, the detonation driver yields an effective sound speed which is $20 \%$ higher than that of the helium used to drive the detonation, however, the effective pressure is only $35 \%$ of the helium value. This indicates that a perfectly driven detonation, when used as a shock tunnel driver, incurs a large pressure performance penalty to achieve sound speeds which are higher than pure helium.

For the SID case in the adjoining figure, the same $30 \%$ argon diluent yields an effective driver pressure approximately $75 \%$ of the light-gas driver pressure, while the effective sound speed remains at about $20 \%$ above the helium value. Thus, a lower pressure performance penalty is required for nearly the same sound speed increase. Note that the SID driver performance curve in Figure $5 \mathrm{~b}$ was calculated with a ratio of helium pressure in the light-gas chamber to initial detonable mixture pressure $\mathrm{P}_{4} / \mathrm{P}_{100}$ held constant at 20. This value was chosen for illustration and because it is below the perfectly driven condition for all diluent mixtures shown. The optimum choice of this ratio depends on the maximum pressure capability of the light-gas driver and detonation tubes and the specific diluent mixture. A value of 20 is optimum for a facility with light-gas driver and detonation tubes of equal strength because the pressure ratio across an oxygen-hydrogen detonation is practically constant at 20 over a wide range of conditions. 


\section{Limitations}

As previously alluded to, there are various limitations on practical operation of both RST and SET facilities. In the case of a RST, driver gas contamination is a paramount concern, as it is not always obvious from the primary measurements in an experiment when the test gas (air) begins to transition to driver gas (e.g., helium). This is currently the subject of renewed attention and research as the new generation of freepiston driven, high enthalpy RSTìs have come on line. However, oxidation, ablation and/or erosion of the nozzle throat turn out to be major concerns for these facilities, as well. Outgassing of metal vapors can become a significant impediment to optical diagnostics at even moderate enthalpy levels.

As also previously alluded to, the duration of useful test time is a major concern in the case of SET facilities. However, in this regard it is the product of test time and flow velocity which is the parameter controlling flow establishment time. Therefore, the diminished test time at high total enthalpy, and correspondingly high velocity, is not as serious a limitation as might first be suspected.

Boundary layer growth on the tube walls is a potential limitation on both RST and SET operation. When working against a fixed overall length for a dual mode facility, it is likely that the shock tube length for the RST mode may be longer than optimum, resulting in greater than necessary shock attenuation. Prior SET experience2 has demonstrated that boundary layer growth in the acceleration tube can produce a rising static pressure, and while it is possible to offset this using expansion waves generated from the driver, it is clearly a deleterious effect that must be dealt with.

\section{Redesign of HYPULSE for Dual-Mode Capability}

Three configurations for HYPULSE operating in SET and RST modes are shown in Figure 6. The original SET configuration is on top, an interim RST configuration, at which facility operation and preliminary calibration data were obtained, is in the middle, and the final dual mode configuration toward which we are working is on the bottom.

The required facility modifications to operate in RST mode consist of:

- elimination of the acceleration tube section,

- placing a converging-diverging nozzle at the end of the shock tube section,

- upgrading the driver recoil dampers to match the higher recoil forces associated with detonation drive for RST operation.

With these modifications completed, preliminary calibration of the RST mode has begun. Further modification of the facility by installing a larger test section to accommodate a hypersonic nozzle and facilitate installation of larger engine models is currently underway.

Three fundamental ground rules governed the facility modifications:

1. No modification should impair recovery of SET operation, and if possible, they should enhance SET operation,

2. Conversion time from RST to SET, or visa-versa, should be no greater than typical time for model removal or installation

3. Minimize cost by making maximum use of available hardware.

The first two ground rules resulted in a RST design which is somewhat unusual, but fully functional, as will be highlighted in the following discussion.

The original HYPULSE "driver tube" is stainless steel, 6.5 inches ID and $8 \mathrm{ft}$ long, and is rated for 20,000 psia. However, the primary diaphragm station has been moved downstream $8 \mathrm{ft}$ to the $16 \mathrm{ft}$ station for RST operation, effectively down rating the driver to 15,000 psia, the rating of the incorporated section of tube. With the addition of a minor adapter piece, the double-diaphragm section can now be placed in either location, to 
provide a $8 \mathrm{ft}$ long light-gas driver for SET operation or a $16 \mathrm{ft}$ long light-gas driver for RST operation. The detonation driver section can be located downstream of the double-diaphragm station in both cases, or can be eliminated if not needed. (However, elimination of the detonation driver section results in a longer than optimum shock tube length and potentially larger viscous attenuation and displacement effects.) It should be pointed out that the shock tubes are stainless steel, 6 inches ID internal and are rated for an operating pressure of 7700 psia. Various tube penetrations for instrumentation, rather than wall thickness, limit their operating pressure. Reinforcement of the penetrations by welding could increase the pressure rating of the tubes, but the 7700 psia limit is adequate to meet current RST reservoir pressure requirements.

The first step, elimination of the acceleration section of the facility was trivial. It was accomplished by moving the detonation driver section diaphragm to the next tube joint downstream of its prior location, and eliminating the acceleration tube diaphragm. A longer detonation driver section (30 ft) and a longer shock tube section (30 ft) was thereby produced without any change in the overall length of the tubes. Recovery of the SET configuration is therefore equally trivial.

Installation of a converging-diverging nozzle throat section at the end of the shock tube posed several unusual problems for which equally unusual, but effective, solutions were found. The conventional RST design strategy is to rigidly link the shock tubes and nozzle to the driver vessel and allow the assembly to recoil as a unit. A slip joint at the end of the nozzle is sometimes used to avoid transmitting the recoil force to the test section, model and dump tank. For reasons which date back to the original design of the HYPULSE facility, slip joints were placed at the 16-ft station, where the double diaphragm is located for RST operation and at the junction of the end of the acceleration tube and the test section/dump tank. (See Figure 6.) The central sections of shock tube and acceleration tube are anchored to the ground by a worm-gear driven jacking section which is used to open the facility for diaphragm changes. When the HYPULSE facility was recommissioned at GASL, these slip joints were used to permit the driver assembly and test/section dump tank to recoil during a run without imposing axial stresses on the rigidly held central tubes. (Due to the inertia of these sections, all motion occurs well after the test period is over.) Changing this arrangement would impose potentially large axial stresses on the tubes for which they were not designed, and was also deemed a violation of the first two ground rules.

Therefore, it was decided to link the nozzle throat section to the test section/dump tank assembly. This required design of a slip joint between the nozzle throat and the end of the shock tube, in a region containing very hot gas at very high pressure. It also required careful consideration of larger impulsive loads of the RST relative to the SET, both in terms of internal stresses which would be imposed on the test section and dump tank, and axial force which must be accommodated by adequate driver and test section recoil systems. Initial calculations showed that the current test section/dump tank complex would require addition of a substantial inertial mass to absorb these stresses and minimize travel.

A nozzle exit diameter of at least 24 inch diameter was desired to meet the Hyper- $X$ engine size requirements and the current design is for an approximately 30 -inch exit diameter nozzle. To accommodate engine models of this size it was decided to install the 84 inch diameter, $19 \mathrm{ft}$ long, "nozzle tank", which was last used at NASA Langley for shock-expansion tunnel operation ${ }^{7}$, as the new test section. A recent photo of this tank is shown in Figure 7. This tank was designed to admit the 6 inch diameter acceleration tube through its upstream endplate and to bolt up to the current test section at its downstream end. Therefore, the design strategy was to install this tank as the new test section but still retain the current test section/dump tank complex as the new dump tank. The new test section/dump tank complex also offered more than adequate mass to handle the 
imposed loads, and no additional inertial mass is required, although new recoil control systems are still necessary for the driver and test sections.

The new test section offers distinct advantages in not only providing ample room forengine models but also in being designed as two pieces, each about $8.5 \mathrm{ft}$ long, connected by a fast-opening, hydraulically operated clamp arrangement. The two sections are each equipped with hydraulic tractor-type drive units for axial motion. Thus, the test section can be readily split wide open for installation/deinstallation of an engine model, and can also be quickly opened for a technician to enter the tank for access to the model.

The tank was not equipped with windows for optical access. Therefore, four pairs of window ports are being cut in the tank. A new engine support system has also been designed to facilitate installation of the models. A drawing of the new test section showing these design features is displayed in Figure 8. Also note that the four window locations have been selected to provide optical access to the inlet, combustor and nozzle sections of a model in either of two model locations. The two locations correspond to two RST nozzle lengths of roughly $6 \mathrm{ft}$ and $12 \mathrm{ft}$, for relatively low Mach numbers for semi-direct connect applications and higher Mach numbers for free-jet applications, respectively, or for SET operation in either tube or tunnel mode.

Although placing the nozzle exit deep inside the test section is unusual, it is also effective and provides conformance with the ground rules. Furthermore, this removes the nozzle expansion from the stress-wave loadpath to the test section.

Returning now to the nozzle throat section, it has been designed to be both effective and versatile. The slip joints shown in Figure 9 will provide adequate sealing based on prior experience with similar arrangements. The throat has been designed in several segments to provide ready access to a clamping station for the nozzle diaphragm (a thin Mylar sheet) and to permit changes in the throat diameter. A 2 inch throat diameter is believed to be the largest practical size consistent with the 6 inch shock tube diameter, and was selected for initial testing. A conical expansion was selected on the supersonic side, at a half-angle of $10^{\circ}$, out to an exit diameter of 6 inches. Various contoured (or conical) expansion sections can be fitted downstream of this station. The nozzle design effort has been supported by NASA Langley personnel exercising a set of FNS and PNS codes available there. GASL has also carried out nozzle designs using a method-of-characteristics code with third order series expansion for the transonic flow and an integral method correction for boundary layer displacement thickness. This has provided an independent check on the FNS/PNS solutions and additionally permitted evaluation of potential chemical and vibrational nonequilibrium effects in the nozzle. Two different approach contours on the subsonic side and two different nozzle diaphragm stations are also being built to evaluate resultant flow quality and duration of contamination-free flow.

Facility Performance in SET Mode and Initial Calibration Results in RST Mode

\section{SET with Ambient Temperature Driver}

Operational data for HYPULSE in conventional SET mode have been extensively reported in previous publications and will only be briefly outlined here. With a room temperature driver operating a SET at high enthalpy, it is possible to access operating conditions which are well suited for aerothermal measurements of hypervelocity re-entry vehicles at high altitude (low Reynolds number). Calibration data at Mach 17 enthalpy conditions using a pure helium driver, at Mach 15 enthalpy level using a helium/nitrogen blend in the driver, and at Mach 19 enthalpy level using a helium/hydrogen blend in the driver can be found in Reference 9. At these conditions the pitot profile is uniform over central 3"diameter of the 6"-tube at the exit. Test times are approximately $0.4 \mathrm{msec}$ and yield slug lengths of approximately 7 feet. (See Figure 3.) The flow within the expansion 
tube is completely laminar at the tube wall Reynolds numbers which characterize these conditions.

At a more moderate enthalpy level corresponding to approximately Mach 13.5, a higher pressure operating condition can be accessed using a hydrogen/helium mixture in the driver ${ }^{9}$. At this condition the test gas boundary layer along the tube wall becomes fully turbulent which significantly reduces the test flow core diameter. Test flow static pressure tends to rise through what should be the period of useful test time. Computational studies have suggested that this is the result of variation in the tube wall displacement thickness with distance behind the interface ${ }^{10}$.

\section{SET with SID Driver}

By implementing the SID-driver technique we have demonstrated access to operating conditions at 20 times higher pressure than are available with a room temperature driver in the Mach 12 to 17 enthalpy range ${ }^{2}$. Typically, 55\% helium with stoichiometric hydrogen/oxygen is used as the detonable mixture. Measured primary shock speeds appear more consistent with predictions based on the post-C-J conditions rather than the plateau region conditions indicating that the post-C-J pressure decay does not affect shock propagation in SET mode. There is also no decay noticeable in the secondary shock speed beyond that normally experienced due to viscous attenuation.

Operation with SID driver allows access to test conditions at pressures where the tube wall boundary layer in the test gas becomes fully turbulent, and as such, pitot pressure profiles exhibit an acceptably uniform core flow over only a very limited range of conditions. Also, as with the high pressure conditions with the room temperature driver, the static pressure tends to rise during the period where the facility wave diagram would predict steady flow.

It was found that this boundary layer-induced pressure increase could be offset by the pressure decay due to the Taylor rarefaction system behind the C-J wave by proper choice of SID-driver operating parameters. This was accomplished by reducing the strength of the shock wave used to initiate the C-J wave by using a nitrogen/helium mixture as opposed to pure helium for the light gas driver. This leads to a larger pressure fall-off behind the C-J wave and more uniform static pressure in the test flow. By the future addition of a skimmer type nozzle to the exit of the expansion tube to expand the more uniform central region of the test flow, the "SID-driven expansion tunnel" will be capable of free-jet testing of complete hypervelocity propulsion models.

\section{RST with Ambient Temperature Driver}

Reconfiguration of the HYPULSE driver, recoil systems, and shock tube end have been completed and calibration begun in RST mode. Test conditions for the facility are required for semi-free jet tests of the Hyper-X vehicle at the flight Mach 10 operating point. Interest also exists in the Mach 7 operating point for cross-facility comparisons. Consequently, initial calibration with detonation drive has focused on a stagnation enthalpy of approximately 4.8 MJ/kg which requires a primary shock speed of $2 \mathrm{~km} / \mathrm{s}$. Tests were also run to investigate the Mach 7,2.4 MJ/kg total enthalpy, test point for which a conventional helium driver was used.

At the present time only the initial conical portion of the nozzle has been completed and installed. The exit diameter of the nozzle is 6 inches which, with the 2-inch diameter throat, yields a nozzle area ratio of 9. The facility was instrumented with pressure transducers along the detonation tube and shock tube. A five probe pitot rake was positioned at the exit of the conical nozzle section.

Initial tests were run in RST mode with a room temperature helium driver alone. Tailored operation at Mach 7 enthalpy with room temperature driver gas would require a mixture of $30 \%$ hydrogen in helium. Such a high hydrogen content mixture is not considered safe for use as a HYPULSE driver gas and consequently pure helium was used for initial test purposes. The 
resulting test condition is overtailored with $M_{s}=4$.

The shock tube, at an L/D of about 120 , is significantly longer than is desirable and significant test-gas boundary layer development and shock speed decay occur before shock reflection. Figure 10 shows a measured nozzle reservoir trace at the Mach 7 condition. Over-tailored operation with a helium driver can be seen by the increasing pressure with time during the initial portion of the trace. After interface equilibration, approximately $58 \%$ of the driver pressure was recovered as nozzle plenum pressure.

Static pressure was measured on a flat plate compression ramp which, for this test, formed an angle of $17^{\circ}$ with the nozzle axis. The plot of the ramp static pressure normalized by the reservoir pressure shows rapid nozzle flow establishment to steady Mach number as is expected for such a small nozzle. Computed test time at this condition based on test gas drainage, where mass loss to the turbulent tube-wall boundary layer has been included by a Mirels' analysis, is approximately 12 ms. The ratio of flat plate static pressure to reservoir pressure is typically a reasonably sensitive measure of helium driver gas arrival, however, the ramp angle used in these tests diminishes that sensitivity somewhat. Theoretical values for the pressure ratio are indicated on the figure for air flow with isentropic exponent $\gamma=1.4$ and for helium flow with $\gamma=1.67$. Some fall-off in the ratio after approximately $6 \mathrm{msec}$ of steady flow may indicate driver gas contamination.

\section{RST with SID-Driver}

Tests were run to achieve a Mach 10 condition using using the SID and results are shown in Figure 11. For the Mach 10 tests the flat plate was aligned at $0^{\circ}$ to the flow axis. Helium was used for the light-gas driver and stoichiometric hydrogen-oxygen with $30 \%$ argon diluent were used in the detonation tube. The primary diaphragm pressure ratio for these tests was 34. Air was the test gas medium and the shock tube was shortened to approximately $L / D=60$, with the upstream portion now occupied by the detonation tube. The flat reservoir pressure trace shows that the detonation driver is tailored at this enthalpy and the static-to-reservoir ratio indicates that flow establishment occurs quickly. Drainage of the test gas is calculated to occur in $6 \mathrm{msec}$ for this test condition.

Pitot pressure profiles were also measured at the Mach 10 conditions. The results from three repeat runs are shown in Figure 12 and indicate that the conical nozzle is creating a reasonably uniform exit plane flow. It should be noted that previous pitot surveys of this nozzle at the Mach 7, condition as reported recently ${ }^{11}$, showed a considerable variation in Mach number across the nozzle. However, sealing problems with the transducers used in those tests were subsequently found and corrected before the data reported here was taken.

To detect driver gas, a laser diode absorption instrument operating near 1.39 $\mathrm{mm} 6$ is being used to sense the arrival of water vapor, which is a significant component of the detonation products. The instrument is located about $2 \mathrm{ft}$. downstream of the nozzle exit plane within a duct which is capturing the central 2 sq-in core of the flow. The device operates by scanning the laser wavelength over a water vapor absorption line at $5 \mathrm{kHz}$. To enhance sensitivity, the frequency modulation spectroscopy technique is used.

At present, contamination data for only one test with this device is available. The measurements are not quantitative, and the first onset of any detectable response by the instrument is being used to flag the presence of water vapor. These measurements, which are considered very sensitive, indicate that the test flow remains contamination-free for only about $2.5 \mathrm{msec}$ of the nominal 6 msec test period at the Mach 10 test condition. This is considered to be a very short period and reasons for such premature contamination are being sought. One possible explanation may be the shape of 
the shock tube endwall where shock reflection occurs at the subsonic side of the nozzle throat. This surface was contoured utilizing the nozzle optimization methodology of Reference 12 so that it resembles a classical bellmouth nozzle. In retrospect, a more planar reflecting surface for the shock may be preferable. A new subsonic contour has been built and calibration data taken, but no water vapor detection measurements have been completed as of the present time.

\section{Test Capabilities of the Dual Mode RST/SET HYPULSE Facility}

The objective of the current facility modifications is to expand the operating envelope of the HYPULSE facility into the lower enthalpy/lower pressure regime corresponding to Mach 5 to 10 flight conditions, retaining the in-place engine test infrastructure, while simultaneously gaining adequate test time by converting from SET to RST operation.

The expanded operating envelope can be expressed on a Mach number-altitude flight simulation chart, taken from Reference 13, which is displayed here in Figure 13. Lines of constant flight dynamic pressure from 200 to 2000 psf are shown for reference, 200 psf being (roughly) the upper altitude limit at which combustion can be sustained in the ramjet mode at the lower end of the speed range (due to reaction rate and flame stability limits) and 2000 psf being (roughly) the lower altitude limit for sustained scramjet operation at the upper end of the speed range based on heating loads. The more darkly shaded block indicates the prior SET operating map for HYPULSE using an unheated driver gas, with calibrated operating points from prior scramjet test programs shown as the open circles. The lighter shaded pair of blocks indicates the anticipated operating range of the upgraded facility employing the SID mode of driving it. The upgraded SET block surrounds the darker block and expands the scramjet test range to higher flight Mach numbers. The RST block stands to the left of the SET block, covering Mach numbers from 5 to about 12. (As discussed earlier, the SID driver is only required above about Mach 7.)
As indicated by this figure, the RST mode, when fully functional and operated at its limits, will complement the SET mode nicely and provide a hypersonic engine test capability covering the airbreathing corridor from about Mach 5 to 25.

\section{Conclusions}

The attributes and requirements of reflected shock tunnels and shock expansion tunnels have been compared, and it has been concluded that the best capabilities can be achieved by operating in the RST mode at simulated flight conditions at the lower end of the hypersonic spectrum and in the SET mode at the upper end of the spectrum. (It is emphasized that in the current context, flight simulation includes duplication of velocity, temperature, pressure and gas composition.) The need for a high performance driver is common to both modes. Although a single facility may not produce optimum conditions in both modes, there are no serious impediments to configuring a facility to operate satisfactorily in both modes, particularly if it is designed to do so.

The feasibility of operating the HYPULSE facility, which was originally designed as a shock-expansion tunnel (SET), as a reflected shock tunnel (RST) has been demonstrated. Work is continuing on facility modifications which will permit reconfiguring between the two operating modes in no more time than a model change usually requires, as well as on installation of a $7 \mathrm{ft}$. diameter test cabin and 30 in. diameter contoured nozzle. These modifications will enable operation of HYPULSE as a hypersonic scramjet engine test cell with flight simulation capabilities from Mach 5 to 25. The overlap in test conditions in the Mach 5 to 8 range with long duration facilities will permit systematic study of the effects of test gas composition, total pressure, wall temperature, etc., as well as affording an opportunity to employ advanced optical diagnostics not easily used in long duration facilities.

Tailored RST operation at Mach 6 conditions has been demonstrated using an unheated 
helium driver gas. Useful (uncontaminated) test time is about $6 \mathrm{msec}$. at this condition. Arrival of helium in the test gas has been inferred from a shift in the pitot-static pressure ratio on an inclined flat plate. Tailored RST operation at Mach 10 conditions has been demonstrated using a newly-developed shock-induced detonation (SID) mode of driving HYPULSE. Useful test time at this condition is only about 2.5 msec, although the reasons for such premature arrival of driver gas are still being investigated. In this case, arrival of driver gas has been detected by using a highly sensitive diode laser-based water absorption instrument. These test conditions are satisfactory in terms of both test time and total pressure to conduct free-jet type tests of the Hyper-X flowpath at Mach 7 and 10 flight conditions upon completion of the remaining facility modifications. However, the nozzle entrance section is being modified to improve shock reflection characteristics and to relocate the nozzle diaphragm station in an attempt to forestall driver gas contamination.

The expanded flight simulation map of the HYPULSE facility, based on the dual RSTSET configuration capabilities and the dual SID and unheated light gas modes of driving the facility, covers virtually the entire hypersonic airbreathing flight corridor.

\section{Acknowledgments}

The work reported here is the result of continuing support from NASA Langley Research Center through the Hyper- $X$ Program Office, and the dedicated and capable efforts of a number of people at NASA and GASL. The authors wish to acknowledge in particular the work by John Calleja, C-Y Tsai, Alex Betti, Chris Cullen, Lou Nucci, Renaldo Perez, Ed Poole and Geroge Stepanoff on the facility modifications and calibration tests and of Chuck McClinton, Doug Dilly, John Korte and Bob Bittner on nozzle design and test requirements.

\section{References}

1. Bakos, R., Calleja, J., Erdos, J., Auslender, A., Sussman, M. and Wilson, G., "Design, Calibration and Analysis of a Tunnel Mode of Operation for the HYPULSE Facility," AIAA 96-2194, New Orleans, LA, June 17-20, 1996.

2. Bakos, R., Calleja, J., Erdos, J., Sussman, M. and Wilson, G., "An Experimental and Computational Study Leading to New Test Capabilities for the HYPULSE Facility with a Detonation Driver," AIAA 96-2193, New Orleans, LA, June 17-20, 1996.

3. Rausch, V, and Hunt, J., "NASA Hyper-X Program," Plenary Session Paper, AIAA 7th International Space Planes and Hypersonic Systems Conference, Norfolk, VA, Nov. 18-22, 1996.

4. Engers, R.J., Calleja, J.F., and Bakos, R.J., A Detonation Driven Injectant heater for Pulse Facility Testing Applications," AIAA 95-3153, July 1995.

5. Tsai, C-Y, Calleja, J.F., Bakos, R.J., and Rogers, R.C., "A Technique for Mixing Measurements in Hypervelocity Pulse Facilities Using Particle Scattering Imagery," AIAA 96-2222, June 1996.

6. Wang, L-G., Trucco, R.E., and Sachse, G.W., "Water Vapor Measurements for Combustion Diagnostics Using a 1350 nm Tunable Siode Laser," Presented at Laser Applications in Combustion and Combustion Diagnostics II, SPIE's OE/LASE "94, January 22-29, 1994.

7. Miller, C.G. and Jones, J.J., "Development and Performance of the NASA Langley Research Center Expansion Tube/Tunnel; a HypersonicHypervelocity Real-GAS Facility," Proc. 14th Int'l Symp. On Shock Tubes and Waves, Sydney, Australia, August 1518, 1983.

8. Mirels, H., "Test Time in Low Pressure Shock Tubes, Physics of Fluids, Vol. 6,No. 9, September 1963. 
9. Erdos, J., Calleja, J., and Tamagno, J., "Increase in the Hypervelocity Test Envelope of the HYPULSE ShockExpansion Tube," AIAA 94-2524, June 1994.

10. Wilson, G.J., Sussman, M.A., and Bakos, R.J., "Numerical Simulations of the Flow in the HYPULSE Expansion Tube," NASA TM-110357, June 1995.

11. Bakos, R.J., Castrogiovanni, A., Calleja, J.F., Nucci, L., and Erdos, J.I., "Expansion of the Scramjet Ground Testing Envelope of the HYPULSE Facility," AIAA 96-4506, November 1996.

12. Korte, J.J., and Hodge, J.S., "Flow Quality of Hypersonic Wind-Tunnel Nozzles Designed Using Computational Fluid Mechanics," Journal of Spacecrafted and Rockets, Vol. 32, No.4, PP. 569-580, July-August 1995.

13. Guy, R.W., Rogers, R.C., Puster, R.L., Rock, K.E., and Diskin, G.S., "The NASA Langley Scramjet Test Complex," AIAA 96-3243, July 1-3, 1996. 


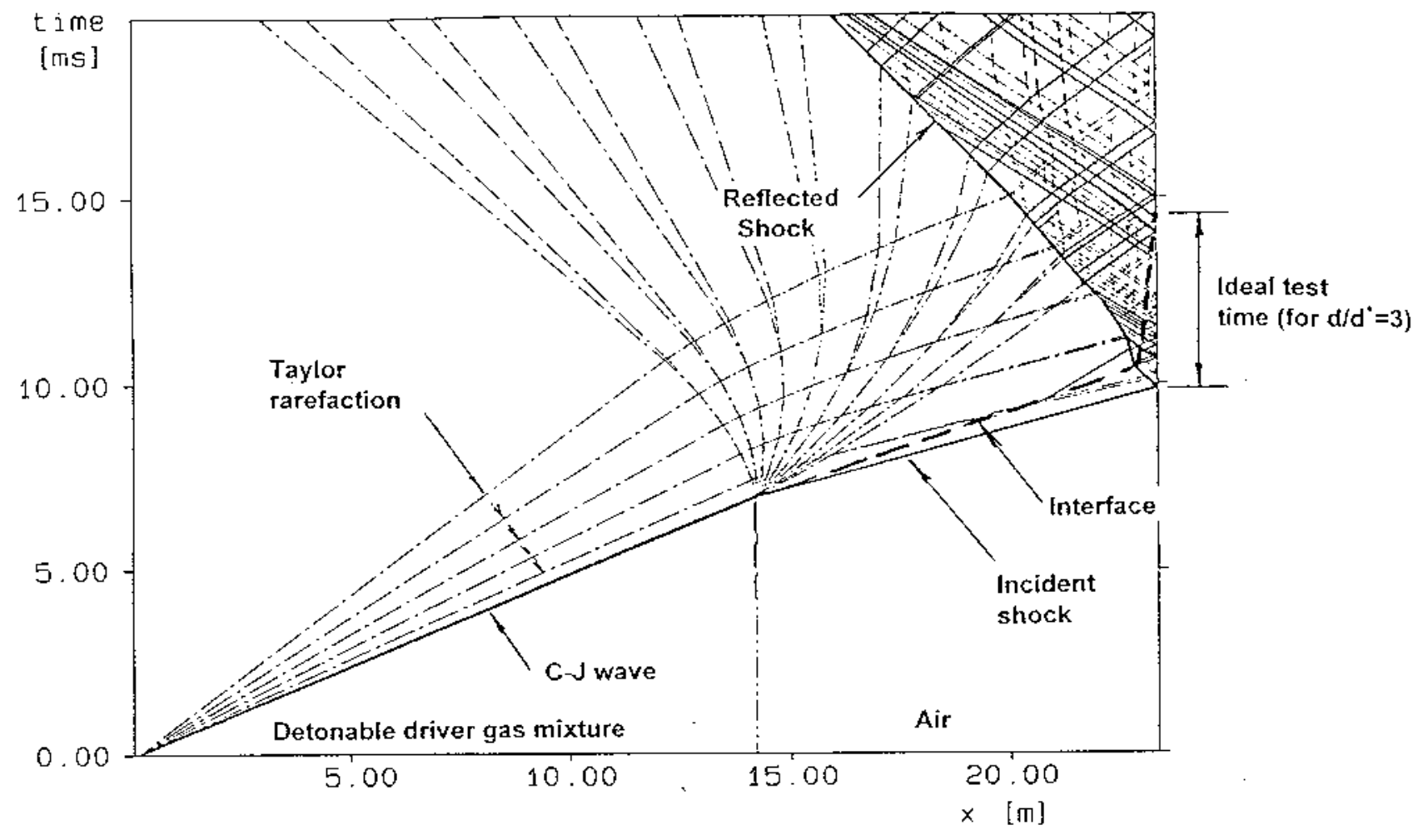

Figure 1. Wave diagram showing reflected shock tunnel operation with a downstream-running detonation wave driver and a 3:1 diameter ration at the throat at a nominal Mach 10 total enthalpy condition.

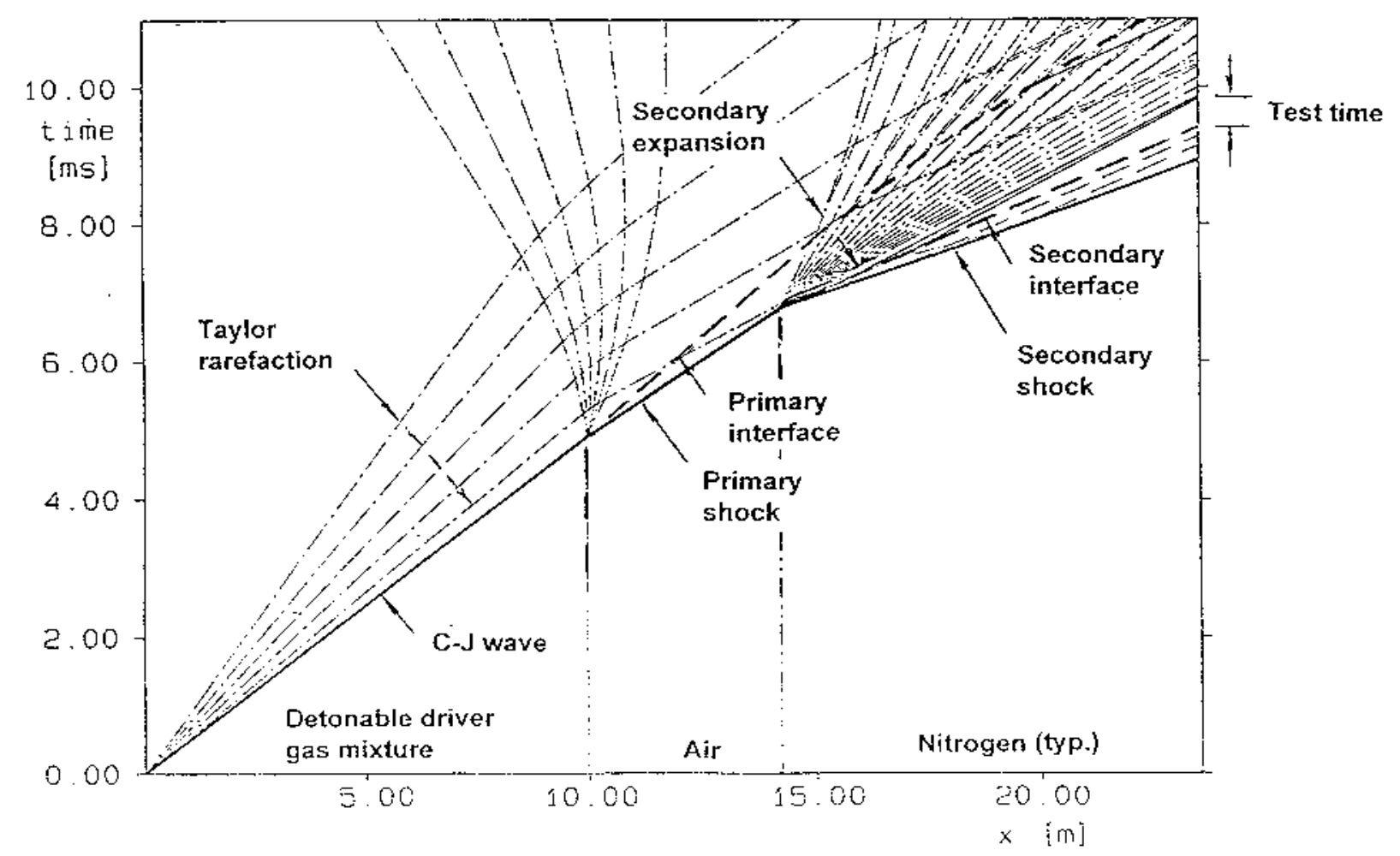

Figure 2. Wave diagram showing shock-expansion tunnel operation with a downstream-rumning detonation wave driver at a nominal Mach 15 total enthalpy condition. 


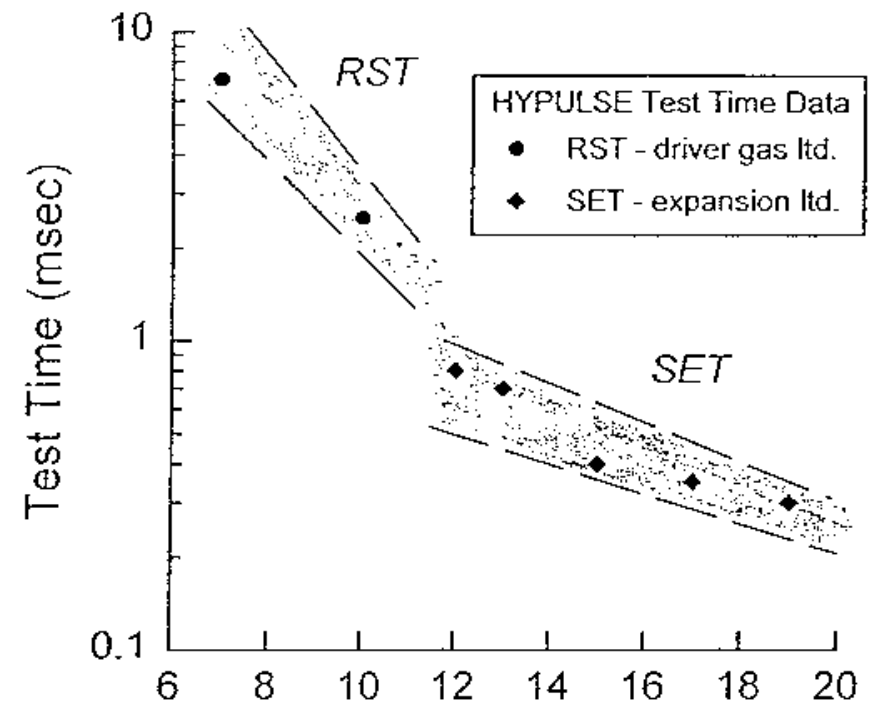

Flight Mach Condition

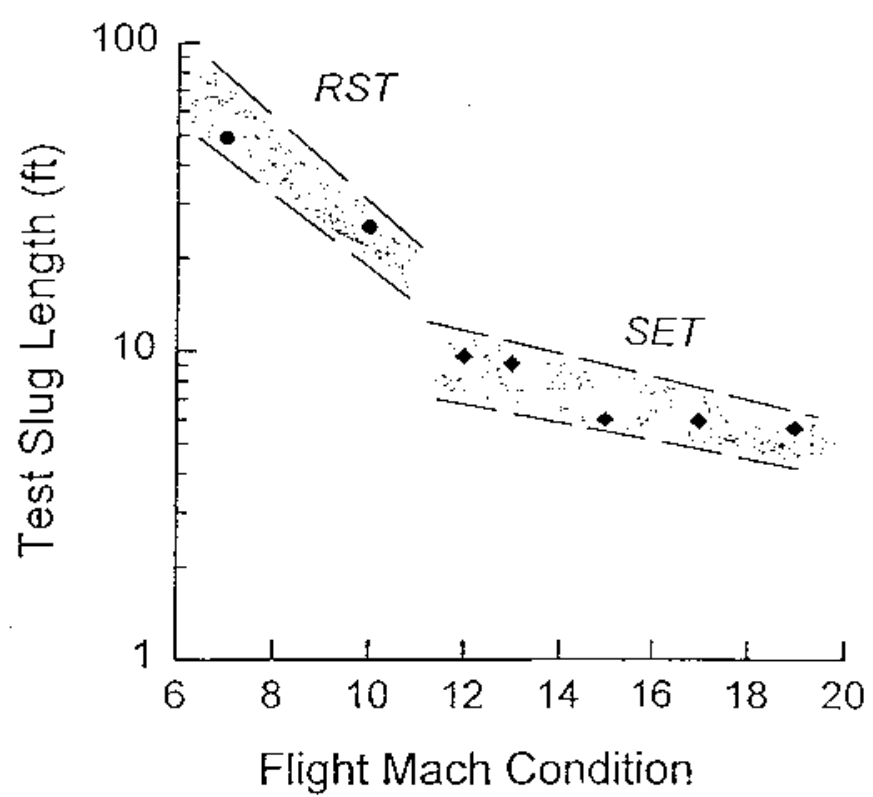

Figure 3. Experimentally determined test time and slug length from HYPULSE in RST and SET modes.

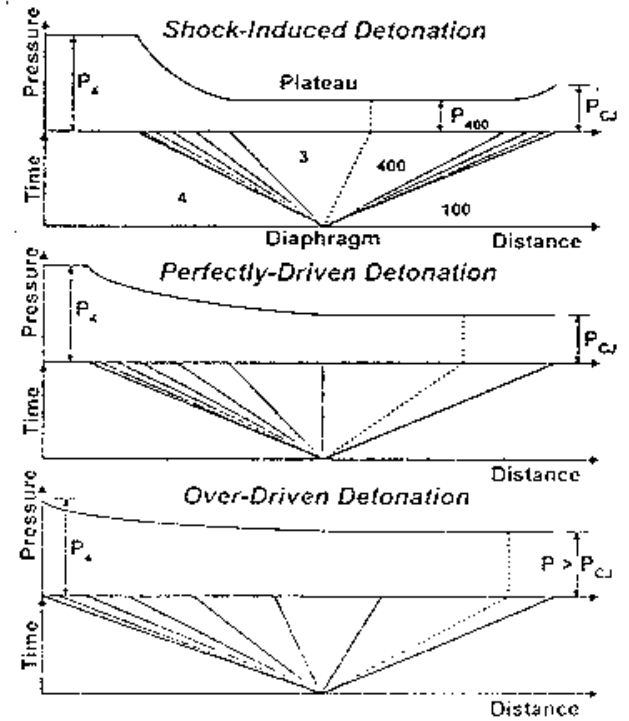

Figure 4. Operation of a Light-Gas Driven Detonation Tube in Shock-induced Detonation (SID), Perfectly Driven, and Over Driven Modes. 


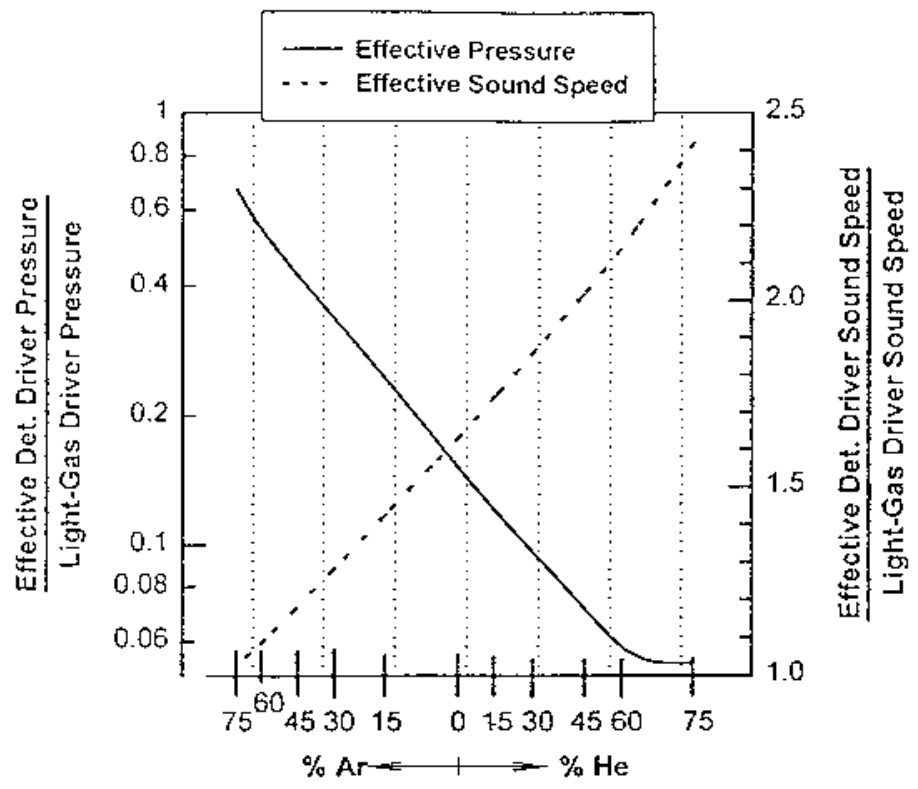

Detonable Mixture Diluent Fraction in $2 \mathrm{H}_{2}+\mathrm{O}_{2}$

Figure 5a. Effective performance of a Perfectly Driven Detonation when used as a Shock Tunnel Driver relative to a Helium: Light-Gas Driver alone.

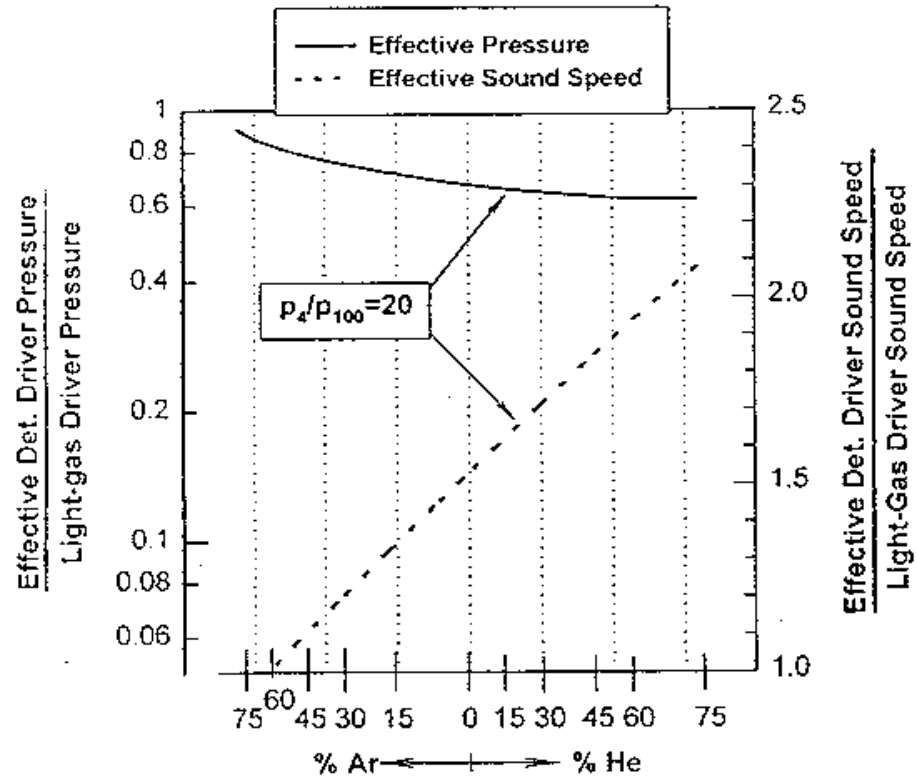

Detonable Mixture Diluent Fraction in $2 \mathrm{H}_{2}+\mathrm{O}_{2}$

Figure 5b. Effective performance of a Shock-Induced Detonation (SID) when used as a Shock Tunnel Driver relative to a Helium Light-Gas Driver alone. 
HYPULSE-SET; Mach 12-25 with 4'-dia. Test Section

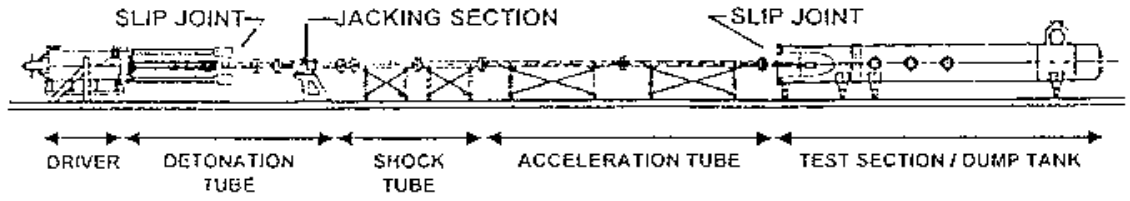

HYPULSE-RST; Mach 5-10 with 4'-dia. Test Section

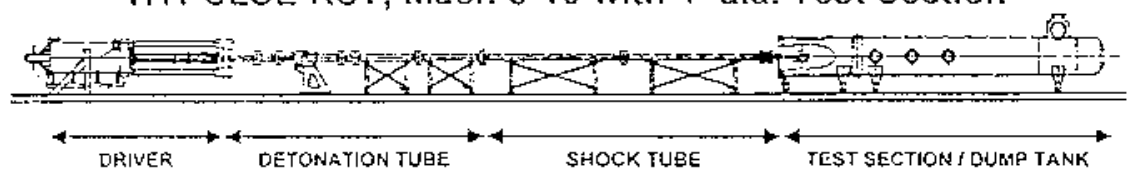

HYPULSE-SET/RST; Mach 5-25 with 7'-dia. Test Section

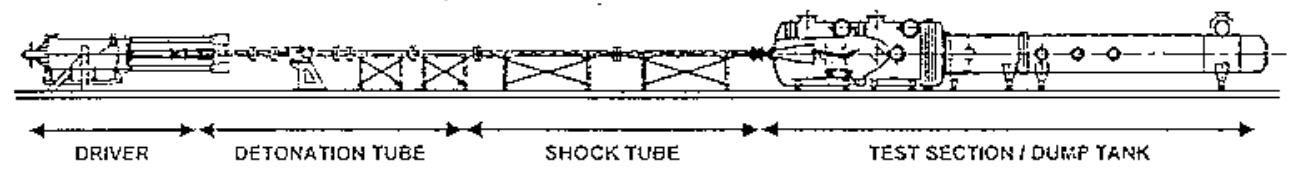

Figure 6. Arrangement and Physical Characteristics of the - HYPULSE Facility.

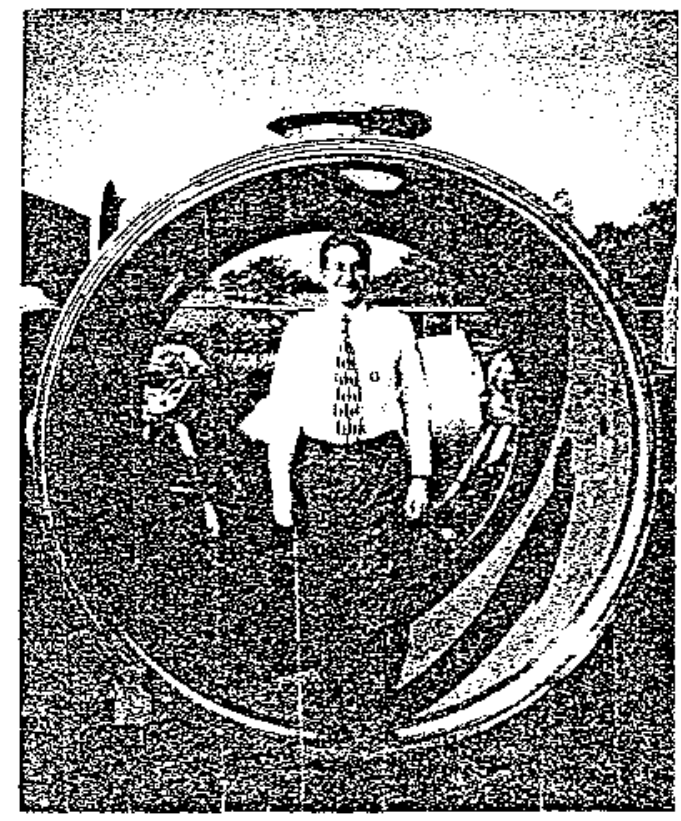

Figure 7. The 84-Inch Diameter Nozzle Tank from the NASA-Langley Expansion Tunnel which will become the New Test Section for HYPULSE SET/RST. 

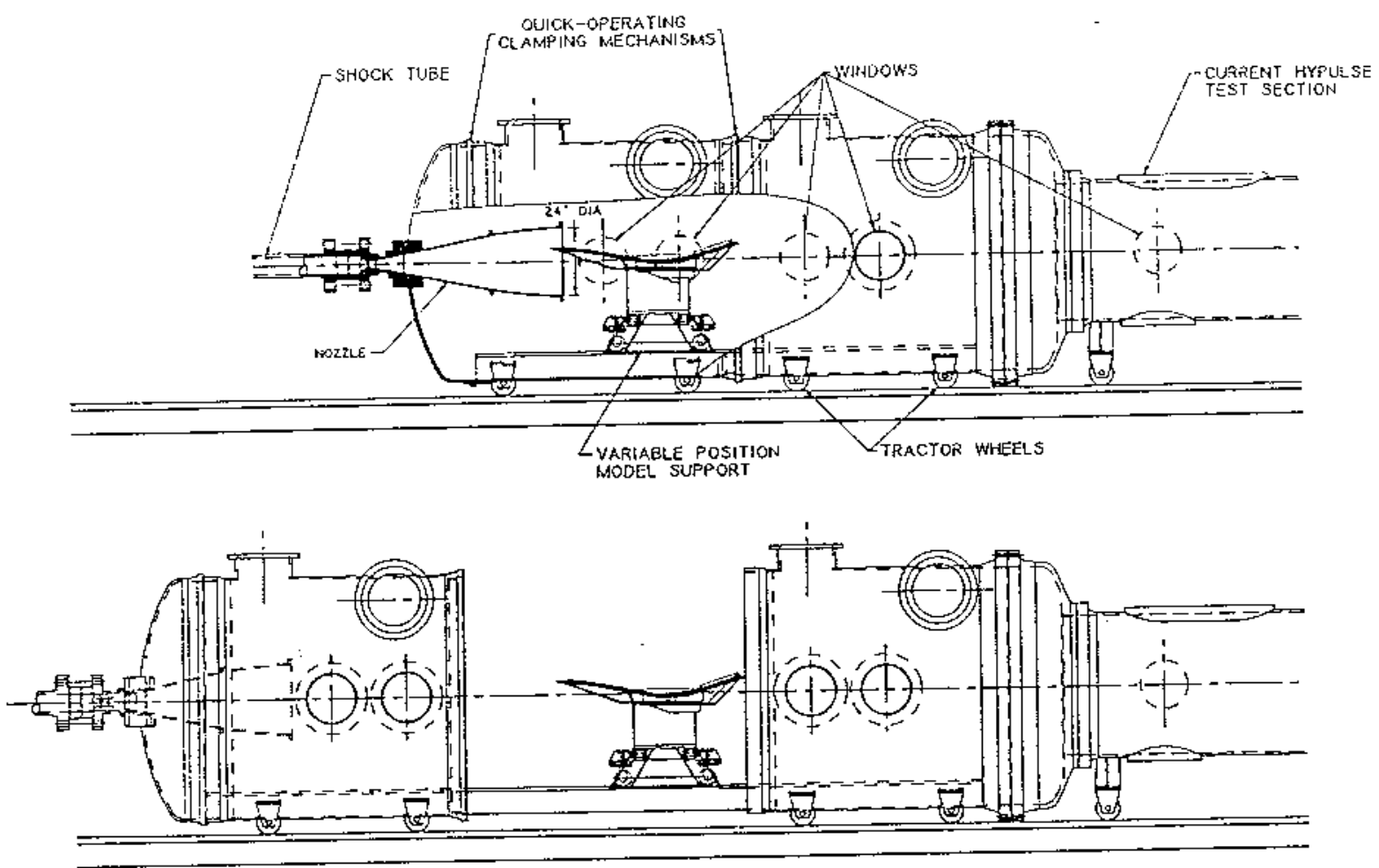

Figure 8. Installation of the 84-inch Test Section in HYPULSE Upstream of the Existing 48-Inch Test Section.

Hydraulically Operated Quick-Opening Clamps allow Easy Access and Model Installation.

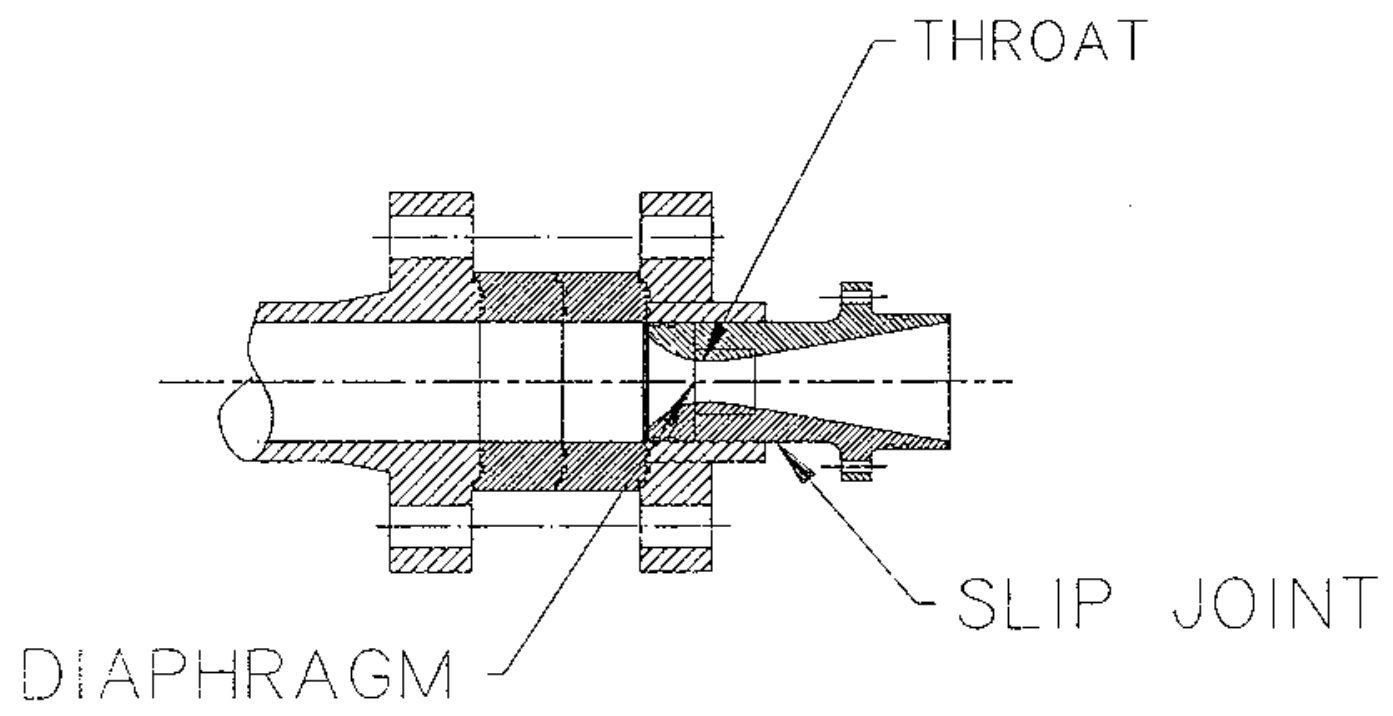

Figure 9. The Throat Region of the RST Nozzle showing the Slip Joint Arrangement which isolates the Shock Tube from Impulsive Axial Loads at Shock Reflection. 

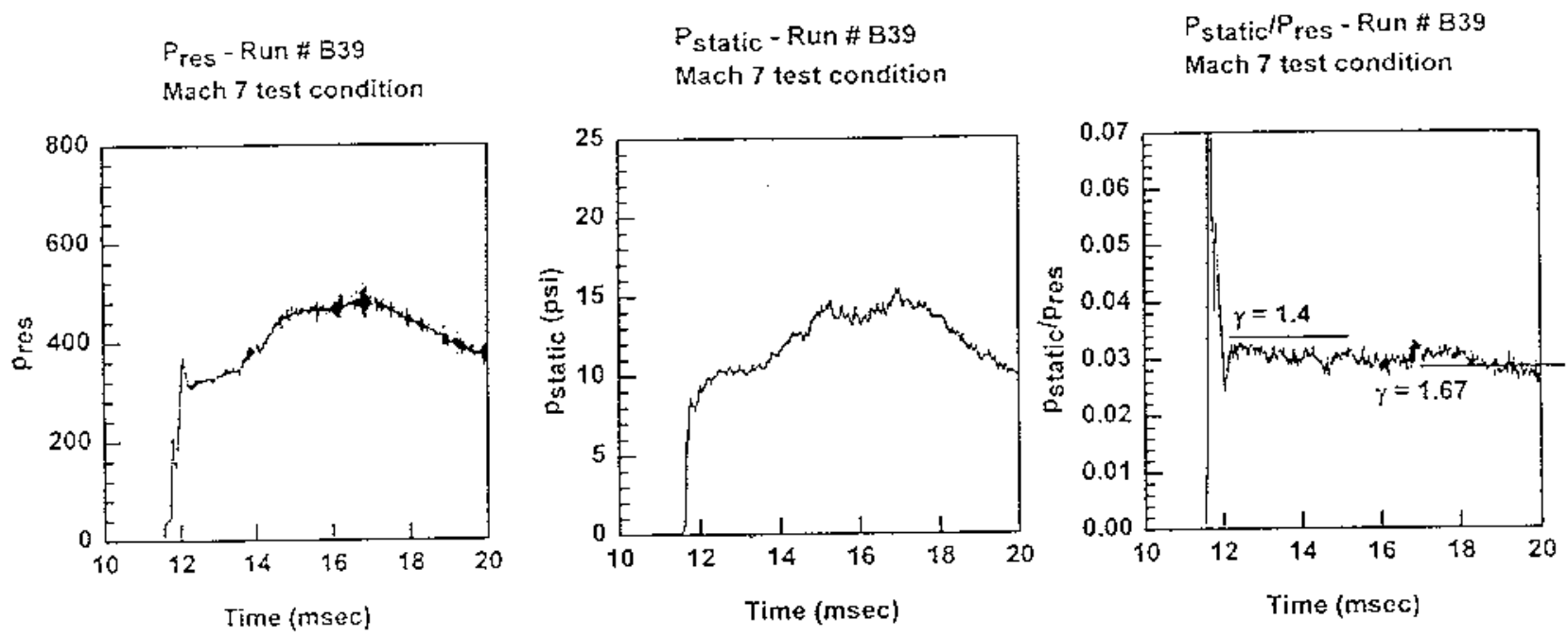

\section{Figure 10. Measured Traces at a Mach $7(2.4 \mathrm{MJ} / \mathrm{kg})$ Test Condition with an Ambient Temperature Helium Driver.}

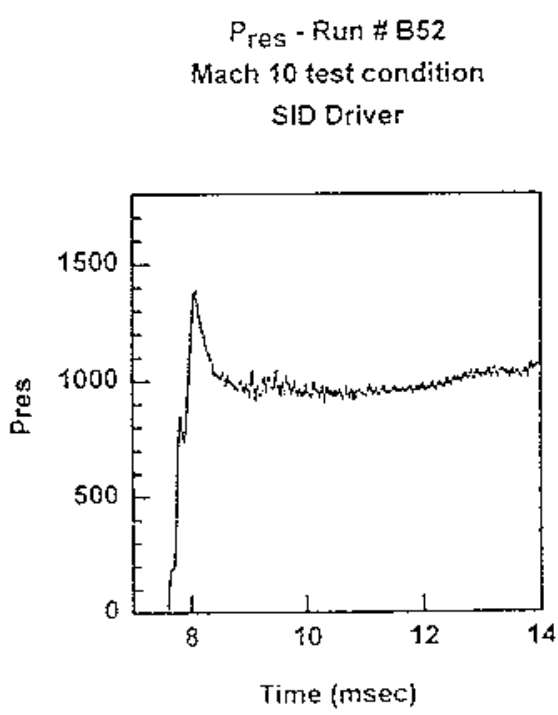

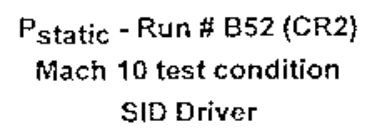

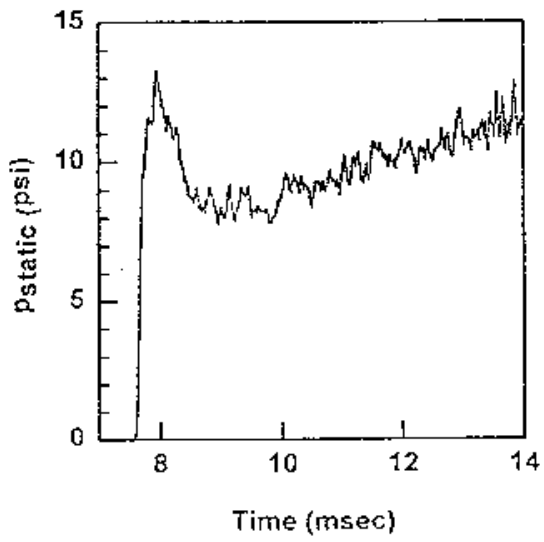

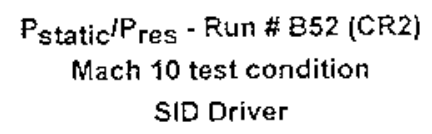

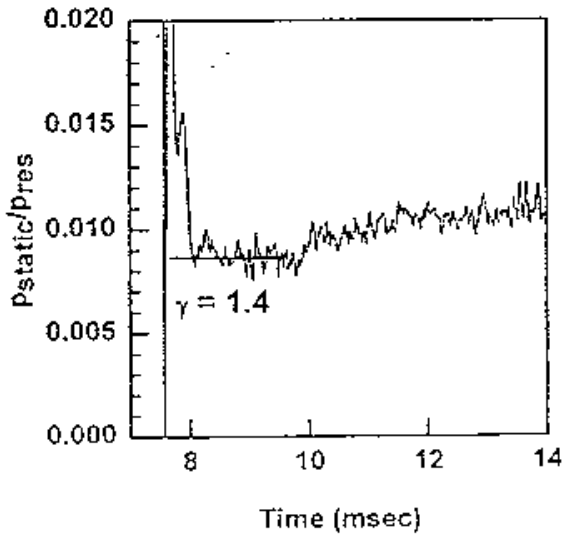

Figure 11. Measured Traces at a Mach $10(4.8 \mathrm{MJ} / \mathrm{kg})$ Test Condition with the SID-driver. 


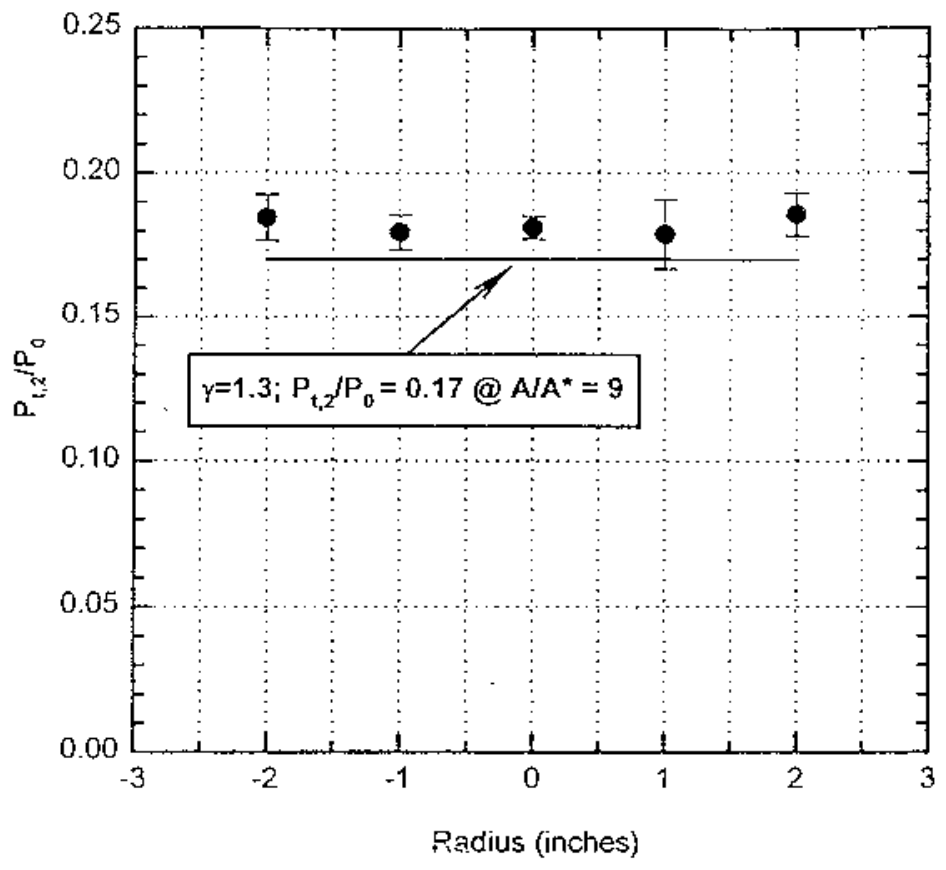

Figure 12. Conical Nozzle Pitot Pressure Profile with SID Tailored Operation at Mach 10 Enthalpy.

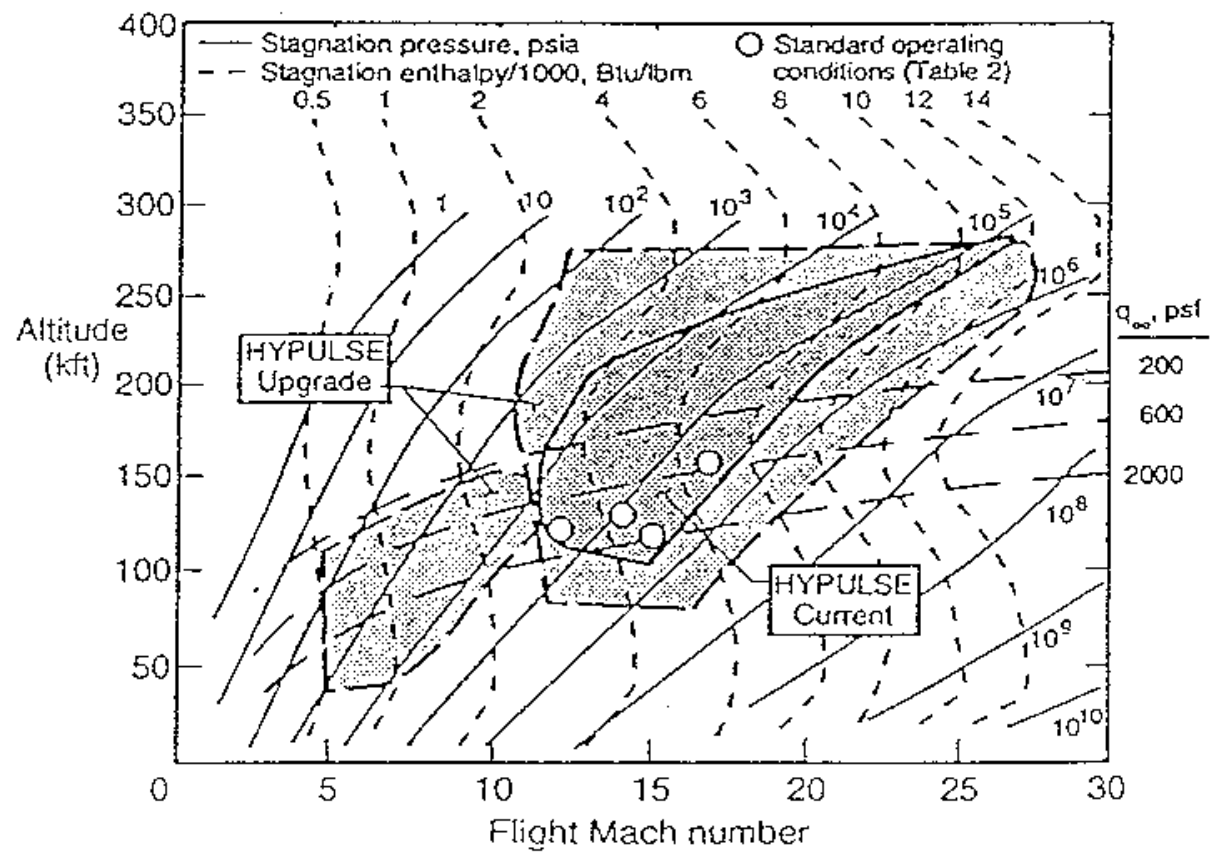

Figure 13. Mach-Number Altitude Chart Displaying HYPULSE Current and Upgrade Simulation Envelopes in SET and RST Modes (from Reference 13). 